\title{
A comparative study of food intake between Lithuanian and Swedish middle-aged men: the LiVicordia study
}

\author{
By Birgitta Elwing, Carin Kullberg, Zita Kucinskiene, \\ Marianne Björegren, Algis Abaravicius and Margareta Kristenson \\ Received: October 18, 2000; Revised: March 20, August 6, 2001; Accepted: September 4, 2001
}

\begin{abstract}
Background: In 1994, the mortality in coronary heart disease was four times higher among Lithuanian middle-aged men than among Swedish men. Over the period 1993-1995, the LiVicordia study investigated possible causes for this difference. We have earlier reported lower serum levels of cholesterol and higher susceptibility of low-density lipoprotein cholesterol for oxidation among Lithuanian men.

Objective: In this part of the study, the aim was to compare mean estimates of food intake.

Design: Cross-sectional study of random samples of 50-year-old men from each of the cities of Linköping, Sweden and Vilnius, Lithuania $(n=150)$. The volunteers were interviewed about their food intake with the 24-hour recall method.

Results: We found no differences in total energy intake, but Vilnius men had a higher energy intake from fat. Vilnius men consumed more fat from meat and less vegetable fat, while fat intake from dairy products was almost the same. Also, Vilnius men had a higher intake of vegetables, while Linköping men had a higher intake of fruit and berries.

Conclusion: The observed differences in food consumption and dietary composition are partly consistent with the higher CHD mortality among Lithuanian men. However, data on biomarkers indicate that other dietary and lifestyle factors play a role.

Key words: Coronary heart disease, Eastern Europe, food interview, nutrition, 24-hour recall
\end{abstract}

\begin{abstract}
Introduction
Serum cholesterol is the most significant determinant of population risk of coronary heart disease (CHD) (1). The most important determinant of serum cholesterol levels is habitual diet, where the quality of fat is more important than the total fat intake. A high intake of saturated fat is strongly related to elevated serum levels of total and low-density lipoprotein (LDL) cholesterol levels, while n-6 polyunsaturated fatty acids reduce serum cholesterol. Diets with a high proportion of saturated fat have likewise been associated with $\mathrm{CHD}$, while a high intake of polyunsaturated fatty acids (PUFA) has been considered to be beneficial with regard to cardiovascular risk. Monyunsaturated fatty acids (MUFA) intake is considered to be neutral with regard to $\mathrm{CHD}$ risk (1). Therefore, nutrition analysis regarding fat quality is important in CHD epidemiological research.

During the last few decades CHD mortality has increased dramatically in Eastern Europe but is declining in Western Europe (2). In 1994 the mortality among 50-year-old-men was four times higher in Lithuania compared to Sweden. The Linköping-Vilnius coronary disease risk assessment study (LiVicordia) was set up to investigate possible explanations for this difference in CHD prevalence. Our comparison between Linköping, Sweden and Vilnius, Lithuania showed that Vilnius men had higher blood pressure and that smoking habits did not differ. Serum levels of total and of LDL cholesterol were lower in Vilnius men
\end{abstract}

Birgitta Elwing ${ }^{1}$, dietician, Carin Kullberg ${ }^{2}, \mathrm{PhD}$, Zita Kucinskiene ${ }^{3}$, Professor, Marianne Björegren ${ }^{4}$, dietician, Algis Abaravicius ${ }^{3}, \mathrm{MD}, \mathrm{PhD}$, Margareta Kristenson ${ }^{1}, \mathrm{MD}, \mathrm{PhD}$.

${ }^{1}$ Division of Social and Preventive Medicine and Public Health Sciences, Department of Health and Environment, Faculty of Health Sciences, Linköping University, ${ }^{2}$ Divisions of Ophthalmology and ${ }^{4}$ Cardiology, University Hospital, Linköping, Sweden, and ${ }^{3}$ the Department of Physiology, Biochemistry and Laboratory Medicine, Medical Faculty, Vilnius University, Vilnius, Lithuania. Correspondence: Margareta Kristenson, Centre for Public Health Sciences, SE-581 85 Linköping, Sweden. E-mail: Margareta.Kristenson@lio.se than in men from Linköping (3). As these populations have a serum level of cholesterol that by international standards is high, they could all be regarded as at high risk of CHD. Our results confirmed previous studies showing that classical risk factors could not explain differences in CHD between Eastern and Western European countries (4).

Differences in CHD prevalence must then be sought in other nutritional factors such as those that affect cholesterol oxidation. As earlier reported, Vilnius men showed, in an in vitro test, a higher susceptibility of LDL for oxidation and lower serum levels of several lipid soluble antioxidant vitamins (3). The main sources of these vitamins are vegetables and bread. PUFA are more prone to oxidation. Therefore, the lower cholesterol levels and the higher susceptibility of LDL cholesterol to oxidation might both be explained by a higher intake of PUFA in the Vilnius diet.

In this part of the LiVicordia study the aim was to compare mean estimates of food intake for the two cities: Linköping, Sweden and Vilnius, Lithuania.

\section{Method and participants \\ Study design}

The LiVicordia study is a cross-sectional investigation of CHD risk factors comparing 50-year-old men from each of the cities Vilnius, Lithuania and Linköping, Sweden $(n=150)$. Random samples of 200 men born between July 1st 1943 and June 30th 1944 were obtained from the census registers of both Vilnius (600 000 inhabitants) and Linköping (130 000 inhabitants). The study was performed in two parts: LiVicordia I included about 100 men from each city and was performed from October 1993 to May 1994; LiVicordia II included another 50 men in each city, chosen from the same random sample of 50-year-old men, and was performed from January to March 1995 . In both parts of the study the same investigations of traditional and new possible risk factors for CHD were performed. LiVicordia II also included an 
Table 1. Instructions for 24 recall in the LiVicordia study.

- The period of time shall correspond to the period of 00.00 to 24.00 the day preceding the interview.

- The interview shall deal with meals consumed in chronological order, beginning with the first occasion and moving on to the last.

- The following aids to serving size estimation shall be used; Household measures; 1, 5, 15 and $100 \mathrm{ml}$, a ruler, packages of butter and margarine 5 and $10 \mathrm{~g}$, and a glass with $150 \mathrm{ml}$ water.

- The interview shall only include entirely open-ended questions; i.e. What did you eat and drink?

Did you eat or drink anything else?

- Supplementary questions can be the following;

Did you have butter or margarine on your bread?

Did you have anything further on your bread?

Did you have anything with your breakfast cereal?

Do you take anything in your coffee or tea?

- And; if the subject have not indicated any beverage; Did you drink anything with your meal?

- In respect to hot meals the following types of supplementary questions can be used;

Did you drink anything with the main dish?

Did you use mustard, ketchup or anything with the main dish?

Did you eat anything else at the same time as the main dish,

for example a side plate?

Did you eat anything before the main dish?

Did you eat anything after the main dish?

- As a round off to each occasion of consumption the interviewer shall repeat the information provided and ask the subject to try to imagine the plate or mealtime and see "if anything is missing".

- After the subject has described his consumption during the entire period, the following checklist shall be used a probe for "between meals" shall be used:

Fast food (hot dogs, hamburgers, kebab)

Fruit (apples, bananas)

Sweets, chocolate and cookies

Beverages (beers, wine, spirits, soft drinks, coffee, tea, milk)

Snacks (crisps, popcorn, peanuts)

Sandwiches, biscuits, etc

Cereals and milk

Ice-cream,

Diet supplements

adipose tissue biopsy from the abdomen. The experimental setup was thoroughly standardised between the two centres. The response rates were: in LiVicordia I, $83 \%$ in both cities, in LiVicordia II, $79 \%$ in Linköping and $64 \%$ in Vilnius. Both Linköping and Vilnius men represent urban populations. In both cases, mortality data for the cities are parallel to national data. Analyses showed that respondents were representative of their populations with respect to education and occupation.

\section{4-hour recall}

Food intake was studied by the 24-hour recall method. This is a retrospective investigation, which is performed as a personal interview (5), see instructions for 24-hour recall in Table 1. Only one interview was conducted with each volunteer, consequently the results can only be used on group level. The interviews were evenly distributed from Monday to Friday, thereby reflecting food consumption from Sunday to Thursday, and the registration was performed during the same periods of the year (LiVicordia I: October-May and LiVicordia II January-March) in both countries. The same interview form was used in both countries. The volunteers were not aware in advance that their consumption on a specific day was to be studied. They were asked to say what they had consumed over the period of 24 hours from 00.00 until
Table 2. Consumption according to 24-hour recall. Group differences were tested by Mann-Whitney tests.

\begin{tabular}{|c|c|c|c|c|c|}
\hline & \multicolumn{2}{|c|}{$\begin{array}{c}\text { Linköping } \\
n=150\end{array}$} & \multicolumn{2}{|c|}{$\begin{array}{l}\text { Vilnius } \\
n=149\end{array}$} & \multirow[b]{2}{*}{$\mathrm{p}^{1}$} \\
\hline & $\begin{array}{c}\text { Mean } \\
\mathrm{g}\end{array}$ & SEM & $\begin{array}{c}\text { Mean } \\
\mathrm{g}\end{array}$ & SEM & \\
\hline Milk/soured milk ( $3 \%$ fat) & 112 & 15 & 195 & 21 & $* * *$ \\
\hline Low fat milk products & 224 & 25 & 0 & 0.0 & $* * *$ \\
\hline Cream & 16 & 2.2 & 18 & 3.1 & ns \\
\hline Hard cheeses & 46 & 4.1 & 8 & 1.5 & $* * *$ \\
\hline Cottage or curd cheeses & 2 & 1.0 & 24 & 4.3 & $* * *$ \\
\hline Butter & 5 & 2.3 & 15 & 1.5 & $* * *$ \\
\hline Margarine & 22 & 1.7 & 4 & 0.7 & $* * *$ \\
\hline Low fat spreads & 8 & 1.1 & 0 & 0.0 & $* * *$ \\
\hline Vegetable oil & 9 & 1.6 & 14 & 2.0 & $* *$ \\
\hline Lard & 0 & 0.0 & 10 & 1.1 & $* * *$ \\
\hline Pork & 42 & 5.5 & 77 & 7.5 & $* * *$ \\
\hline Beef & 34 & 4.8 & 33 & 5.7 & ns \\
\hline Sausages & 36 & 5.1 & 39 & 5.6 & ns \\
\hline Other kinds of meat & 8 & 3.0 & 24 & 4.9 & $* *$ \\
\hline Fish & 47 & 6.7 & 21 & 4.0 & $* *$ \\
\hline Eggs & 19 & 2.8 & 33 & 3.8 & $* * *$ \\
\hline Vegetables & 93 & 8.0 & 135 & 10.8 & $* * *$ \\
\hline Fruit and berries & 158 & 13.1 & 101 & 13.7 & $* * *$ \\
\hline Pulses & 6 & 2.9 & 0 & 0.0 & $*$ \\
\hline Potatoes & 181 & 12.7 & 224 & 20.6 & ns \\
\hline Root vegetables & 24 & 3.6 & 43 & 5.0 & $* * *$ \\
\hline Nuts, almonds & 2 & 0.7 & 2 & 0.8 & ns \\
\hline Bread & 140 & 6.6 & 188 & 8.9 & $* * *$ \\
\hline Flour, oats, pasta & 60 & 6.6 & 39 & 4.7 & $*$ \\
\hline Biscuits, cakes & 61 & 5.4 & 19 & 3.4 & $* * *$ \\
\hline Sugar & 25 & 6.5 & 31 & 2.3 & $* * *$ \\
\hline Sweets & 11 & 1.8 & 5 & 1.5 & $* * *$ \\
\hline Ice-cream & 8 & 2.5 & 0 & 0.0 & $* * *$ \\
\hline Coffee & 598 & 33.6 & 157 & 13.6 & $* * *$ \\
\hline Lemonade, soda & 145 & 24.5 & 53 & 9.9 & $*$ \\
\hline
\end{tabular}

$1 * * *=\mathrm{p}<0.001 ; \mathrm{ns}=$ not significant

24.00 the day and night preceding the interview. The interview form was open-ended and the general questions were "What did you eat and drink?" and "Did you eat or drink anything else?" Further supplementary questions and probes such as "Did you have any snacks during the day?" were used to assist the volunteer in recalling what he had consumed. After the volunteer had described his consumption, a checklist was used to remind him in case he had forgotten anything, for example sweets, ketchup, candies, fruit, ice-cream, etc.

The recall method was carefully standardised by using the same checklist, and through practical training in interview techniques. To estimate serving sizes, aids such as household measures, portion packages of margarine and butter and a ruler were used.

\section{Choice of foodstuffs}

All 24-hour recall interviews from the Vilnius group were translated from Lithuanian to Swedish before food choices were categorised. A Lithuanian native speaker living in Sweden carried this out. In order to compare the choice of food, 30 food categories were defined. The choice of categories was mainly based on the groups defined in the Swedish Food and Nutrition tables. As foodstuff groups needed to be able to reflect the food habits in both countries, a few categories were split, e.g. the category "milk" into "low fat milk" and "full fat milk", after observations of the availability of food in the two countries. 
Table 3. Energy intake reported at the 24-hour recall.

\begin{tabular}{llccccc}
\hline & & \multicolumn{2}{c}{$\begin{array}{c}\text { Linköping } \\
\mathrm{n}=150\end{array}$} & \multicolumn{2}{c}{$\begin{array}{c}\text { Vilnius } \\
\mathrm{n}=149\end{array}$} \\
& & Mean & SEM & Mean & SEM & $\mathrm{p}$ \\
& & & & & & \\
\hline Energy intake & $\mathrm{MJ}$ & 10.1 & 3.0 & 10.0 & 3.7 & $\mathrm{~ns}$ \\
Protein & $\mathrm{g}$ & 90 & 29 & 73 & 28 & $* * *$ \\
Protein & E\% & 15 & 2.9 & 13 & 3.1 & $* * *$ \\
Carbohydrates & $\mathrm{g}$ & 273 & 86 & 243 & 97 & $* *$ \\
Carbohydrates & E\% & 46 & 7.7 & 43 & 10.3 & $* *$ \\
Fat & $\mathrm{g}$ & 99 & 38 & 112 & 53 & $*$ \\
Fat & E\% & 35 & 6.9 & 43 & 12.5 & $* * *$ \\
Alcohol & $\mathrm{g}$ & 11 & 19 & 12 & 26 & \\
Alcohol & E\% & 3.0 & 4.6 & 3.0 & 5.6 & $\mathrm{~ns}$ \\
& & & & & & \\
\hline
\end{tabular}

$\mathrm{E} \%=\%$ of energy intake

Table 4. Estimated PAL-values according to physical activity at work and during leisure time, as reported in a questionnaire. Italic figures represent PAL-values, figures in parentheses represent number of cases in Linköping and Vilnius, respectively, attributed the PAL estimate. $n=149$ (L), 147 (V).

\begin{tabular}{|c|c|c|c|}
\hline \multirow[b]{2}{*}{ During work } & \multicolumn{3}{|c|}{ During leisure time } \\
\hline & $\begin{array}{l}\text { 1. Sitting } \\
\text { still }\end{array}$ & $\begin{array}{l}\text { 2-3. Some } \\
\text { physical } \\
\text { exercise }\end{array}$ & $\begin{array}{l}\text { 4. Intensive } \\
\text { physical } \\
\text { exercise }\end{array}$ \\
\hline $\begin{array}{l}\text { 1. Sitting still/ } \\
\text { unemployed }\end{array}$ & $\begin{array}{c}1.4 \\
\text { (L } 10 / \text { V 28) }\end{array}$ & $\begin{array}{c}1.5 \\
\text { (L 57 / V 27) }\end{array}$ & $\begin{array}{c}1.7 \\
(\mathrm{~L} 1 / \mathrm{V} 1)\end{array}$ \\
\hline $\begin{array}{l}\text { 2-3. Standing } \\
\text { and/or walking }\end{array}$ & $\begin{array}{c}1.7 \\
\text { (L 13 / V 23) }\end{array}$ & $\begin{array}{c}1.7 \\
\text { (L 57 / V 58) }\end{array}$ & $\begin{array}{c}2.0 \\
(\mathrm{~L} 2 / \mathrm{V} 0)\end{array}$ \\
\hline $\begin{array}{l}\text { 4. Heavy manual } \\
\text { labour }\end{array}$ & $\begin{array}{c}2.0 \\
(\mathrm{~L} 1 / \mathrm{V} 6)\end{array}$ & $\begin{array}{c}2.0 \\
(\mathrm{~L} 8 / \mathrm{V} 4)\end{array}$ & $\begin{array}{c}2.3 \\
(\mathrm{~L} 0 / \mathrm{V} 0)\end{array}$ \\
\hline
\end{tabular}

\section{Energy intake}

The Swedish tables for the calculation of nutrient intake are based on the Swedish Food and Nutrition Tables and were calculated with the aid of the computer program "Dietist". In Lithuania, the computer program "Computerised dietary analysis system for calculation of nutrient intake" was used. The nutrition tables used in this program are from various sources, both Russian and Lithuanian. In Vilnius, a specially trained person conducted the interviews. The Lithuanian researcher who had participated in the standardisation of the study coded the results. In Sweden two dieticians did both the interviews and coding.

\section{Energy assessment}

The accuracy of food recordings in the two study groups was assessed by comparisons of estimated total energy expenditure and observed total energy intake per day. All calculations were based on the assumption that the study population as a whole was in energy balance $(6,7)$. To estimate total energy expenditure $\left(\mathrm{TEE}_{\mathrm{est}}\right)$ for a person, the basal metabolic rate $\left(\mathrm{BMR}_{\mathrm{est}}\right)$ was calculated. If the participant had a body mass index (BMI) of $>25 \mathrm{~kg} / \mathrm{m}^{2}$, the body weight (BW) corresponding to $\mathrm{BMI}=25$ was used. The following equation is adapted for men 31-60 years old (6), where $\mathrm{BW}_{\text {corr }}$ represents the corrected body weight: $\mathrm{BMR}_{\text {est }}=0.0485 \times \mathrm{BW}_{\text {corr }}+3.67$

The physical activity level (PAL) value represents physical activity during work and leisure time over a period of 24 hours.
Estimates of PAL were based on two questions in a questionnaire regarding physical activity during work and leisure time respectively. Each question had four answer alternatives, ranging from very low activity, i.e. mainly sitting still, to very strenuous physical activity. Based on the different combinations of activity during work and leisure time, PAL values were attributed according to guidelines (6). The estimated total energy expenditure (TEE) was calculated as (6) $\mathrm{TEE}=\mathrm{BMR}_{\text {est }} \times \mathrm{PAL}$

The observed total energy intake (TEI) was calculated from the 24-hour recall and compared with the $\mathrm{TEE}_{\text {est }}$. To estimate the accuracy of the observed energy intake, two comparisons were made. First an estimate of how much physical activity the reported energy intake would correspond to (observed energy intake/BMR ${ }_{\text {est }}=P A L_{\text {est }}$ ), and secondly, the estimated energy expenditure was calculated, based on the physical activity reported in the questionnaire (PAL $\left.x \mathrm{BMR}_{\mathrm{est}}=\mathrm{TEE}_{\mathrm{est}}\right)$.

\section{Statistical methods}

Group means were compared with Student's t-test if normally distributed, otherwise with the Mann-Whitney test. Calculations were made with the SPSS computer program (v.9.01, SPSS Inc 1999).

\section{Results}

\section{Choice of foodstuffs}

In Table 2, intake from different food categories is presented. Differences between the two countries were found particularly in fat sources and intake of carbohydrates. Linköping men consumed more milk. However, two thirds was low fat milk $(0.5 \%)$, while Vilnius men only used full fat milk. Linköping men ate more hard cheese (46 vs. $8 \mathrm{~g}, \mathrm{p}<0.001$ ) and more ice-cream, but less cottage or curd cheese than Vilnius men did. For cooking, baking and as spread, Vilnius men used lard, butter and vegetable oil, while Linköping men used mainly margarine and low fat spreads. Vilnius men also ate more pork (42 vs. $77 \mathrm{~g}, \mathrm{p}<0.001$ ), meat and eggs, but less fish. In addition, Vilnius men ate more vegetables, especially root vegetables, while Linköping men ate more fruit and berries. Bread consumption was higher in Vilnius, while Linköping men ate more cereals, pasta and rice, as well as cakes and biscuits. There was more "visible" sugar in the diet of Vilnius men, such as sugar in coffee or tea, while Linköping men ate more sweets and consumed more soft drinks. Linköping men had a higher intake of coffee.

Based on these data on choices of foodstuff, we made estimations of proportions of fat intake from different fat sources. Vilnius men had a higher proportion of fat intake from meat products (59 vs. $25 \%$ ). While the absolute intake of dairy products was about the same, the relative amount of fat intake from dairy products was higher in Linköping men (27 vs. 18\%). Linköping men had a higher proportion of fat intake from vegetable fat $(31 \%)$, mainly from margarine, compared to Vilnius men (15\%). In Linköping a large proportion of fat $(17 \%)$ came from mixed sources, mainly biscuits and cakes, with a fat composition corresponding to margarine. In Vilnius $8 \%$ of fat came from mixed sources.

\section{Energy intake}

There was no difference in total energy intake between Vilnius and Linköping men. However, Vilnius men had a higher fat intake (43 vs. $36 \mathrm{E} \%, \mathrm{p}<0.001$ ), and a corresponding lower intake of protein (13 vs. $15 \mathrm{E} \%, \mathrm{p}<0.001)$ and carbohydrates (43 vs. $46 \mathrm{E} \%, \mathrm{p}=0.001)$. The energy contribution from alcohol was similar, $3 \mathrm{E} \%$ in both cities (Table 3). 


\section{Energy assessments}

PAL-values, assigned according to the questions on physical activity, are given in Table 4. Based on these values, the estimated energy expenditure in both countries would be approximately $12 \mathrm{MJ}$. According to the 24-hour recall, the observed energy intake was approximately $10 \mathrm{MJ}$ in both cities (Table 5). The difference between estimated energy expenditure and observed intake was in both cities 1.9 MJ.

\section{Discussion}

\section{Eastern and Western European countries}

To our knowledge, this is the first study to compare comprehensive and individual-based data on food intake between Eastern and Western European countries. Results from the 24hour recall showed no difference in total energy intake between the men in Linköping and Vilnius, but a higher energy intake from fat in Vilnius men (43 vs. $35 \mathrm{E} \%$ ). Vilnius men had a higher intake of fat from meat and a lower intake of vegetable fat, while the intake of dairy products was almost the same. Also, Vilnius men had a higher intake of vegetables, while Linköping men had a higher intake of fruit and berries.

Our results are in line with earlier studies; in Sweden, two large national surveys were performed during the time period of the LiVicordia study: HULK 1989 and Riksmaten 1997-8. Our results on choices of food are in line with both these studies. Likewise, the observed energy intake and energy percent for macronutrients among Swedish men in our study is very close to results in the above-mentioned studies (8). The results for Lithuanian men are also supported by earlier research: nutrition research on Kaunas city inhabitants in 1992-1993, using a 7-day dietary recall method, found a similar intake of milk and dairy products, meat, fish, vegetable oil, and vegetables in the inhabitants of Kaunas as we found in Vilnius men (9).

Furthermore, in earlier studies, populations in Eastern Europe (Estonia and Russian Karelia) had a higher intake of butter compared to a Western European population (Finland) (10). Similar differences were found in the present study. However, taking into account all possible fat sources, Linköping men had as high a fat intake from dairy products as Vilnius men, mainly because of the high consumption of hard cheese among Linköping men. Data from the Food and Agricultural Organisation database 1961-1990 also showed small differences in mean consumption of dairy products between Eastern and Western European countries (4). Linköping men had a higher intake of fish compared to Vilnius men. The estimated levels are also in line with results from earlier national studies $(8,9)$. These levels were low in both cities, and the fish consumed by the Swedes had a low fat content. Therefore it is unlikely that differences in fish intake can explain lipid levels.

\section{Fat quality}

As Lithuanian food tables were not complete, we were unable to determine fat quality from food interviews. To estimate the longterm quality of fat intake and the amount of essential fatty acids, we included an analysis of fatty acids in adipose tissue biopsies in the second part of the LiVicordia (II) study. As earlier reported, we found small differences in the content of linoleic acid and linolenic acid. Vilnius men had higher PUFA/SAT ratio (P/S 0.43 vs. 0.39 ) and a lower percentage of saturated fatty acids (3.4 vs. $4.6 \%$ ) in their adipose tissue (11). This is not consistent with the higher intake of meat among Vilnius men. A possible reason for discrepancies between reported food intake and analysis of adipose tissue could be that biopsies were taken only in LiVicordia II. We compared the data for LiVicordia I and II and there were no significant differences between the two surveys concerning energy content or food composition.
Table 5. Comparisons of observed energy intake and estimated expenditure. For calculations of basic metabolic rate, the weight for cases with $\mathrm{BMI}>25 \mathrm{~kg} / \mathrm{m}^{2}$ was recalculated to correspond to $\mathrm{BMI}=25 \mathrm{~kg} / \mathrm{m}^{2}$. The PAL-estimate refers to the amount of physical activity that can be performed with the energy intake reported in the 24-h recall. The estimated energy expenditure refers to how much energy is needed to perform the amount of physical activity reported in the questionnaire.

\begin{tabular}{|c|c|c|c|c|c|c|}
\hline & & \multicolumn{2}{|c|}{$\begin{array}{l}\text { Linköping } \\
n=150\end{array}$} & \multicolumn{2}{|c|}{$\begin{array}{c}\text { Vilnius } \\
n=149\end{array}$} & \multirow[b]{2}{*}{$\mathrm{p}^{9}$} \\
\hline & & Mean & $\mathrm{SD}$ & Mean & $\mathrm{SD}$ & \\
\hline $\mathrm{BW}^{1}$ & $\mathrm{~kg}$ & 80.5 & 11.9 & 82.4 & 11.8 & ns \\
\hline $\mathrm{BMI}^{2}$ & $\mathrm{~kg} / \mathrm{m}^{2}$ & 25.3 & 3.4 & 27.0 & 3.3 & $* * *$ \\
\hline$B W_{\text {corr }}^{3}$ & & 76.2 & 7.4 & 74.9 & 6.1 & ns \\
\hline $\mathrm{BMR}_{\text {est }}{ }^{4}$ & MJ & 7.4 & 0.36 & 7.3 & 0.30 & ns \\
\hline $\mathrm{TEI}^{5}$ & $\mathrm{MJ}$ & 10.1 & 3.0 & 10.0 & 3.7 & ns \\
\hline $\mathrm{PAL}_{\text {est }}$ & $\left(\mathrm{TEI} / \mathrm{BMR}_{\mathrm{est}}\right)$ & 1.4 & 0.39 & 1.4 & 0.51 & ns \\
\hline $\mathrm{PAL}^{6}$ & & 1.6 & 0.15 & 1.6 & 0.16 & ns \\
\hline $\mathrm{TEE}_{\text {est }}{ }^{7}$ & MJ & 12.0 & 1.2 & 11.9 & 1.2 & ns \\
\hline Difference $^{8}$ & & 14.9 & 2.9 & 15.0 & 4.1 & ns \\
\hline
\end{tabular}

\author{
Body Weight; ${ }^{2}$ Body Mass Index \\ 3 Body Weight Corresponding to BMI $<25 \mathrm{~kg} / \mathrm{m}^{2}$ \\ 4 Basal Metabolic Rate (0.0485 x BW \\ 5 Total Energy Intake (observed) \\ 6 Physical Activity Level, based on activity questions (Table 4) \\ 7 Total Energy Expenditure (BMR ${ }_{\text {est }}$ X PAL) (estimated) \\ 8 Difference between estimated and observed energy intake \\ (TEE est TEI) $\times 100 /$ TEI $\%$ of estimated intake \\ $9 * * *=\mathrm{p}<0.001 ; \mathrm{ns}=$ not significant
}

\section{CHD mortality}

A fourfold difference between Lithuania and Sweden in CHD mortality, with small differences in the quality of fat intake, is a paradox. The same kind of paradox has been found when comparing France and Finland. A possible explanation of this paradox, given that both populations have a high level of fat intake, was suggested to be that differences in antioxidant capacity affect LDL oxidation and thereby atherogenesis (12). Several surveys have shown Eastern European populations to have a high intake of cereals and vegetables, but a lower intake of fruit and fresh vegetables $(4,13)$. Low serum levels of antioxidant vitamins have also been reported (14). In our study, Vilnius men, compared to Linköping men, had lower serum levels of the lipid soluble antioxidant vitamins $\beta$-carotene, lycopene, and tocopherols (3). The main sources of these vitamins are yellow, red and green vegetables, vegetable oil and bread. According to reported food intake of vegetables and bread, the intake of these vitamins should have been higher among Vilnius men. The higher serum level of tocopherols among Linköping men could partly be explained by differences in fat sources. In Sweden the main fat source was margarine in which rapeseed oil is a main ingredient, while in Lithuania the main fat source was meat products.

\section{Serum levels of vitamins}

Another possible explanation for differences in serum levels of vitamins is that food preparation affects absorption. In Vilnius the vegetables are often eaten boiled in soups, or as "sauerkraut", while in Linköping the vegetables were often eaten raw in salads. It is not known whether these differences affect vitamin availability, and our results from the 24 -hour recall could not explain serum differences in lipid soluble antioxidant vitamins between Vilnius and Linköping men. The higher intake of fruit 
and berries among Swedish men may, in this context, be important because of their content of water-soluble antioxidant C-vitamin.

\section{Assessments of food intake}

Assessments of food intake are by many regarded as one of the most difficult tasks in population surveys, and the importance of validating recorded data on energy intake against estimation of energy needs has been stressed $(7,15)$. With the help of PAL measures, we compared reported energy intake against calculated energy need and found, in both cities, an underestimation of $15 \%$. This is similar to what has been reported in several earlier studies (15), and indicates that the estimation of total energy intake was conducted with the same precision in both study groups.

The Swedish Food and Composition Tables cover the energy and nutrients of over 1100 foodstuffs while Lithuanian tables, at the time of the study, covered about 300 . In addition, Lithuanian tables only contained data concerning fat quality in a small number of items. Therefore, we could not use these tables for comparisons of micronutrients between the two countries. At the time of the study there were obvious economic and cultural differences between the two countries. Food in Lithuania was more expensive in relation to income, and there were fewer choices of foodstuffs in the shops compared to Sweden. This is mirrored in the differences in complexity of nutrition tables, but is also a possible confounding factor.

We worked carefully to standardise each part of the procedure. Still, differences in the researchers' conditions may have led to a reduced comparability of results. In Vilnius, the second

\section{REFERENCES}

1. Grundy SM: Lipids, Nutrition, and Coronary Heart Disease. In: Fuster V, Ross R, Topol EJ, eds. Atherosclerosis and Coronary Heart Disease. Philadelphia: Lippincott-Raven Publishers; 1996.

2. UNICEF: Crises in mortality, health and nutrition. Florence, 1994

3. Kristenson M, Ziedén B, Kucinskiene Z, Schäfer-Elinder L, Bergdahl B Elwing B, et al: Antioxidant state and mortality from coronary heart disease in Lithuanian and Swedish men: concomitant cross-sectional study of men aged 50. BMJ 1997;314:629-633.

4. Ginter E: Cardiovascular disease prevention in Eastern Europe. Nutrition 1998:14:452-7.

5. Callmer E, Hagman U, Haraldsdòttir J, Bjørge Løken E, Seppänen R, Trygg $\mathrm{K}$ : Proposal for the standardisation of 24-hour recall and similar interview methods. Vår Föda 1986;4:259-68.

6. WHO: Energy and Protein requirements. Report from a joint FAO/WHO/ UNO expert consultation. WHO Technical Report Series; 724. Geneva; 1985.

7. Hambraeus L: Dietary assessments: how to validate primary data before conclusions can be drawn. Scand J Nutr 1998;42:66-8.

8. Becker W: Svenskarna äter allt nyttigare - allt fler väljer grönt. Vår Föda 1999;1:24-7. (In Swedish)

9. Abaravicius A, Cerniauskiene LR, Varskeviciene Z, Domarkiene S, Kad- language was Russian, while in Linköping it was English. This caused some difficulties when standardising the method. In Vilnius, one cookery book with recipes for different dishes was used while coding the results. In Sweden the recipes came from different sources. The main sources were the Swedish Food and Composition Tables containing data of prepared dishes, or directly from the volunteers. In addition, in about $20 \%$ of cases, the actual recipe used was obtained by the dietician calling the men's wives or the restaurant where they had eaten. Thus, the Vilnius data reflect a general Lithuanian diet while the Linköping data is more individually based, which can be a cause of bias. However, our aim was to compare mean estimates for the two cities, not individual data. Both cities had the same precision in reported energy intake and our results from comparisons of food choices are similar to results from national samples in both countries.

\section{Conclusion}

In conclusion, compared to Linköping men, Vilnius men had a higher intake of fat. Vilnius men had a higher intake of fat from meat and less vegetable fat, while the intake from dairy products was almost the same. In addition, Vilnius men had a higher intake of vegetables while Linköping men had higher intake of fruit and berries. The observed differences in food consumption and dietary composition are partly consistent with the higher CHD mortality among Lithuanian men. However, data on biomarkers indicate that other dietary and lifestyle factors play a role.

\section{ACKNOWLEDGEMENT}

This study was supported by grants from The Swedish Medical Research Council no. 06962. skiauskiene K, Maskeliunas J: Nutritional status of Kaunas city inhabitants Acta Med Lith 1999;2:91-6.

10. Puska P: Health promotion challenges for countries of the former Sovie Union: results from collaboration between Estonia, Russian Karelia and Finland. Health Prom Internat 1995;10:219-28.

11. Kaminskas A, Zieden B, Elwing B, Kristenson M, Abaravicius A, Bergdah $\mathrm{B}$, Olsson AG, Kucinsiene Z: Adipose tissue fatty acids in men from two populations with different cardiovascular risk: the LiVicordia study. Scand J Clin Lab Invest 1999;59:1-6.

12. Artaud-Wild SM, Connor S, Sexton G, Connor W: Differences in coronary mortality can be explained by differences in cholesterol and saturated fat intake in 40 countries but not in France and Finland, a paradox. Circulation 1993;88:2771-9.

13. Rayner M, Petersen S: European cardiovascular disease statistics, 2000 edition. Oxford: British Hearth Foundation; 2000.

14. Bobak M, Brunner E, Miller NJ, Skodova Z, Marmot M: Could antioxidants play a role in the high rates of coronary heart disease in the Czech Republic? Eur J Clin Nutr 1998;52:632-6.

15. Briefel RR, Sempos CT, McDowell MA, Chien S, Alaimo K: Dietary methods research in the third National Health and Nutrition Examination Survey, underreporting of energy intake. Am J Clin Nutr 1997;65:1203S-1209S. 